\title{
Coastal marine gravity modelling from satellite altimetry - case study in the Mediterranean
}

DOI: https://doi.org/10.1515/jogs-2020-0200

Received November 30, 2018; accepted April 26, 2019

\begin{abstract}
The coastal marine gravity field is not well modelled due to poor data coverage. Recent satellite altimeters provide reliable altimetry observations near the coast, filling the gaps between the open ocean and land. We show the potential of recent satellite altimetry for the coastal marine gravity modelling using the least squares collocation technique. Gravity prediction error near the coast is better than $4 \mathrm{mGal}$. The modelled gravity anomalies are validated with sparse shipborne gravimetric measurements. We obtained $4.86 \mathrm{mGal}$ precision when using the altimetry data with the best coastal coverage and retracked with narrow primary peak retracker. The predicted gravity field is an enhancement to EGM2008 over the coastal regions. The potential improvement in alti- metric marine gravity will be beneficial for the next generation of EGM development.
\end{abstract}

Keywords: Coastal marine gravity, Least squares collocation, Satellite altimetry

\section{Introduction}

Marine gravity anomalies are of great importance for studying the Earth's tectonic structure and ocean bathymetry (Døssing et al., 2014; Engen et al., 2006; Parker, 1973; Sandwell et al., 2014b; Smith and Sandwell, 1994). Satellite altimetry measurements are the main source in recovering short wavelength components of the marine gravity field. The traditional altimetry (footprint larger than $10 \mathrm{~km}$ ) can only reach up to $30 \mathrm{~km}$ away from the coast leaving a data gap near the shore. Since the launch of CryoSat-2 in 2010 (Wingham et al., 2006), with the novel Synthetic Aperture Radar (SAR) mode,

\footnotetext{
*Corresponding Author: Adili Abulaitijiang: Institut für Geodäsie und Geoinformation, University Bonn, Nussallee 17 D-53115 Bonn, Germany, E-mail: abulaitijiang@geod.uni-bonn.de Ole Baltazar Andersen: DTU Space, Technical University of Denmark, Lyngby, DK-2800, Denmark

Riccardo Barzaghi: Politecnico di Milano, Milan, Italy

Per Knudsen: DTU Space, Technical University of Denmark, Lyngby, DK-2800, Denmark
}

we can obtain reliable altimetry data benefiting from the high along track resolution (only $\sim 300 \mathrm{~m}$ ). SARAL/Altika (Verron et al., 2015) has smaller footprint and higher range precision than the conventional Ku-band radar altimeters. Therefore, limiting the data gap is possible with a combination of recent altimetry satellites like CryoSat-2 and SARAL/Altika.

The development of marine gravity field requires better altimetric range precision and data coverage. The improved range precision can be achieved by optimal retracking methods. Hwang et al. (2006) highlighted the importance of retracking methods in the coastal marine gravity field modelling around Taiwan. Studies show great improvement in coastal altimetric products by optimized data processing strategy (Bouffard et al., 2008; Gommenginger et al., 2011; Vignudelli et al., 2005). Passaro et al. (2014, 2018) developed adapted waveform retrackers that perform well both for the oceans and coastal waveforms.

Andersen and Knudsen (2000) highlighted the role of satellite altimetry in the gravity modelling using the Geosat and ERS-1 geodetic missions and compared the altimeter-derived gravity anomalies with marine and airborne gravimetric measurements in coastal regions characterized by the narrow continental shelf and shallow water areas, respectively. However, its ability degraded within roughly $10 \mathrm{~km}$ of the coast. Hirt $(2010,2013)$ investigated the role of topography/bathymetry model in gravity field determination in coastal zones, and showed that the bathymetry data were beneficial for filling the gap between terrestrial and shipborne gravity data. Although CryoSat-2 showed great potential for coastal mean dynamic topography (MDT) modelling (Idžanović et al., 2017), coastal geoid determination remains problematic in some areas due to the poor data coverage between land and open ocean areas.

In this paper, we show the potential of marine gravity modelling near the coastal zones from recent satellite altimetry. The Least Squares Collocation (LSC) method is used for the derivation of gravity anomalies from the measured sea surface heights. Residual Terrain Modelling (RTM) is considered in the modelling process. For CryoSat2, three different altimetry datasets are used to examine the 
effect of waveform retrackers in marine gravity modelling. In the final step, the predicted gravity anomalies are validated against shipborne measurements and EGM2008.

\section{Methods}

We model the coastal gravity field within the framework of remove-compute-restore (RCR) methodology (Omang and Forsberg, 2000; Schwarz et al., 1990; Sjöberg, 2005).

The altimetry measurements, Sea Surface Heights (SSH) can be split into several components as follows

$$
S S H=N^{E G M}+N_{r}+M T D^{E G M}+N^{R T M}+\in(t)+e
$$

where $N^{E G M}$ is geoid height from an Earth Gravitational Model (EGM), MDT EGM is the mean dynamic topography associated with EGM, $N_{r}$ is the residual height anomaly, $N^{R T M}$ is contribution from topography, $\in(t)$ is the time dependent components that can be diminished by post processing procedures such as the cross-over adjustment (Knudsen and Brovelli, 1993), $e$ is the error term remaining in the data.

In the remove step, the EGM geoid height, MDT and contributions from Residual Terrain Modelling (RTM) are removed from the original data to reduce the signal. We choose EGM2008 (Pavlis et al., 2012) as the reference model. The MDT model associated with EGM2008 has a maximum spherical harmonic degree and order (d/o) 180. The RTM (Forsberg, 1984; Forsberg and Tscherning, 1981) is considered for reducing the height anomalies, which accounts for the local features that have the shorter wavelengths than that of EGM removed earlier. As for the detailed terrain model, SRTM (Shuttle Radar Topography Missions) (3" $\times 3$ ") and GEBCO (General Bathymetric Chart of the Oceans) $\left(30^{\prime \prime} \times 30^{\prime \prime}\right)$ are combined to de- rive a uniform digital terrain model (DTM) with a spatial resolution of $3^{\prime \prime} \times 3^{\prime \prime}$ over land and ocean. The cross-over adjustment follows right after the RTM approach.

After the signal reduction and cross-over adjustment procedures, we have the "clean" residual height anomalies $N_{r}$, and only the residual gravity field is modelled in the computation step. Two techniques can be used to convert the height anomalies to gravity anomalies, which are the Fast Fourier Transform (FFT) method (Forsberg and Sideris, 1993; Schwarz et al., 1990) and Least Squares Collocation (LSC) method (Basic and Rapp, 1992; Forsberg and Tscherning, 1981; Moritz, 1978). The advantage of LSC is that it can handle heterogeneous observations and the observations are not necessarily gridded as in the case of FFT. Moreover, LSC provides the error estimates of the predicted signal quantity. The disadvantage of LSC is that it requires intensive computational power, as the size of the normal equation increases with the number of observations.

In its simplest form, the LSC can be represented in the form of

$$
\Delta g=C_{(\Delta g, h)}\left[C_{(\Delta g, h)}+D_{(h, h)}\right]^{-1} h
$$

where $C(\cdot)$ denotes the covariance function, $D(\cdot)$ denotes the noise variance of the observations $h$. $h$ in the equation refers to the residual height anomaly $N_{r}$ in Eq.(1).

The covariance function modelling is a crucial step in the LSC. A covariance model is fitted to the empirical covariance estimates (Knudsen, 1987) from the observations. There are several covariance models available, e.g., (Duquenne et al., 2005; Jordan, 1972; Kearsley, 1977), but the model proposed by Tscherning and Rapp (Tscherning and Rapp, 1974) is sufficient in our modelling. The covariance of the anomalous potential $T$ between the two points $P(\phi, \lambda, r)$ and $Q\left(\phi^{\prime}, \lambda^{\prime}, r^{\prime}\right)$ is given by

$$
\begin{aligned}
& \operatorname{Cov}\left\{T_{P}, T_{Q}\right\}=\alpha \sum_{n=2}^{1080}\left(\sigma_{n}^{E R R}\right)^{2}\left(\frac{R^{2}}{r r^{\prime}}\right)^{n+1} P_{n}(\cos \psi) \\
& +\sum_{n=1081}^{\infty}\left(\sigma_{n}^{T R}\right)^{2}\left(\frac{R^{2}}{r r^{\prime}}\right)^{n+1} P_{n}(\cos \psi)
\end{aligned}
$$

where $\alpha$ is the scaling parameter to be estimated, $\left(\sigma_{n}^{E R R}\right)^{2}$ are the error degree variances from the EGM2008 model, $\left(\sigma_{n}^{T R}\right)^{2}$ are the degree variance model proposed by Tscherning and Rapp, $R$ is the mean earth radius, $P_{n}(\cos \psi)$ is the Legendre polynomials with $\psi$ being the spherical distance between the two points.

In the restore step, we need to add back what we have removed. Specifically, the reference gravity anomalies from EGM2008 and RTM gravity anomalies are computed and added to the predicted gravity anomalies from LSC (or FFT). Thus, the full wavelength marine gravity is attained by the RCR approach.

\section{Coastal marine gravity modelling}

Since we are working on the coastal zone, the altimetry tracks terminate near the coastline. Hence, gridding of the altimetry data is not recommended. Therefore, the FFT method is not considered in this work. We make use of the along track data which are non-uniformly scattered and unstacked.

So far we have 8 years of CryoSat-2 data available, but using all the altimetry observations yield large covariance matrix, which is hard to invert in LSC. Data downsampling 

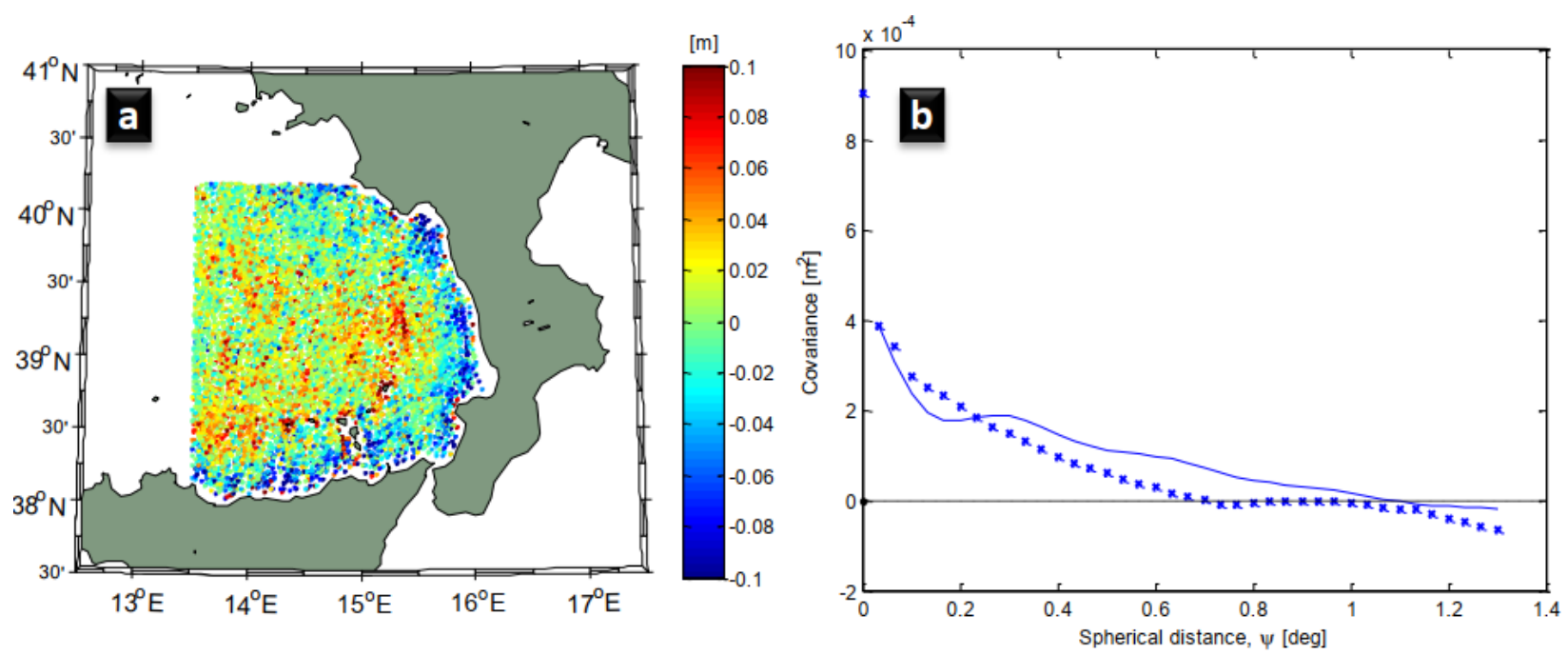

Fig. 1. (a) Residual height anomaly after cross-over adjustment for only removing the EGM2008 model (d/o 2190). (b) empirical covariance (* symbols) and Tscherning\&Rapp covariance model fitting (curved lines).

(or thinning) is an option, but the behaviour of empirical covariances also changes before and after downsampling. For the altimetry data we use two years (2014 and 2015) of CryoSat-2, one year of SARAL/Altika drifting phase and one year of Jason-1 geodetic mission data for the modelling. The precision of observations from different satellite missions are slightly different. For instance, Jason-1, a traditional Ku-band radar altimeter, has a large footprint and $6 \sim 7 \mathrm{~cm}$ range precision (Garcia et al., 2014), while the Ka-band SARAL/Altika has the 3 $4 \mathrm{~cm}$ range precision (Zhang and Sandwell, 2017), which is similar to the CryoSat-2 SAR mode observations. Jason- 1 has a $66^{\circ}$ orbit inclination while the other two satellite have near polar orbits. The inclusion of Jason-1data is important as it provides more inter-satellite crossover points in a small region, which is beneficial for thecross-over adjustment.

The RTM is conducted by prism integration (Forsberg, 1984). The terrain correction (TC), cross-over adjustment (CRSADJ), empirical covariance estimation (EMPCOV), covariance fitting (COVFIT), geodetic collocation (GEOCOL) modules from GRAVSOFT package (Forsberg et al., 2008) are extensively used for the marine gravity modelling.

For the study area, we selected the north of Sicily island with geodetic boundaries $13.5^{\circ}<\lambda<16.2^{\circ}$ and $38^{\circ}<$ $\phi<40.2^{\circ}$. The Aeolian Islands in the Tyrrhenian Sea are located in the center of tested area which is bounded by the Italian Peninsula on the east. The area spans more than $200 \mathrm{~km}$ in both latitude and longitude direction. CryoSat-2 operates in the SAR mode in the study area.

\subsection{Data preparation}

CryoSat-2 data can be obtained from several sources. Firstly, the altimetry data is extracted from Radar Altimeter Database System (RADS) (Scharroo et al., 2013). It is a database for all types of altimetry missions. The CryoSat2 SAR mode acquisitions are processed by a technique called Reduced-SAR (RDSAR, Scharroo (2016)) in the RADS database. Secondly, we use the Lars Altimetry Retracking System (LARS) altimetry database developed at DTU, where CryoSat- 2 waveforms are retracked with different empirical retrackers. For the LARS data, we choose the narrow primary peak retracker (Jain et al., 2015) that produces SSHs with the least along track noise (meaning better range precision). Last but not least, we ordered CryoSat-2 data from Grid Processing On Demand (GPOD) service (https://gpod.eo.esa.int/) maintained by European Space Agency (ESA). In RADS, the waveforms are retracked with a modified Brown retracker (Brown, 1977), while a physical retracker dedicated for the coastal areas, i.e., SAMOSA+ (Ray et al., 2015) is employed in the GPOD service. The GPOD data has the best height precision $(<2 \mathrm{~cm})$ than the other two datasets. Moreover, the Jason- 1 and SARAL/Altika data are extracted from RADS only. CryoSat2 observations retrieved from three different datasets are merged with SARAL/Altika and Jason-1 data and the combined datasets are identified by the names RADS, LARS and GPOD in the following. Only $1-\mathrm{Hz}$ observations are used for marine gravity modelling.

We initially tested the altimetry data (SSHs) from RADS and removed the EGM2008 geoid heights up to d/o 2190 and MDT associated with EGM2008. The residual 

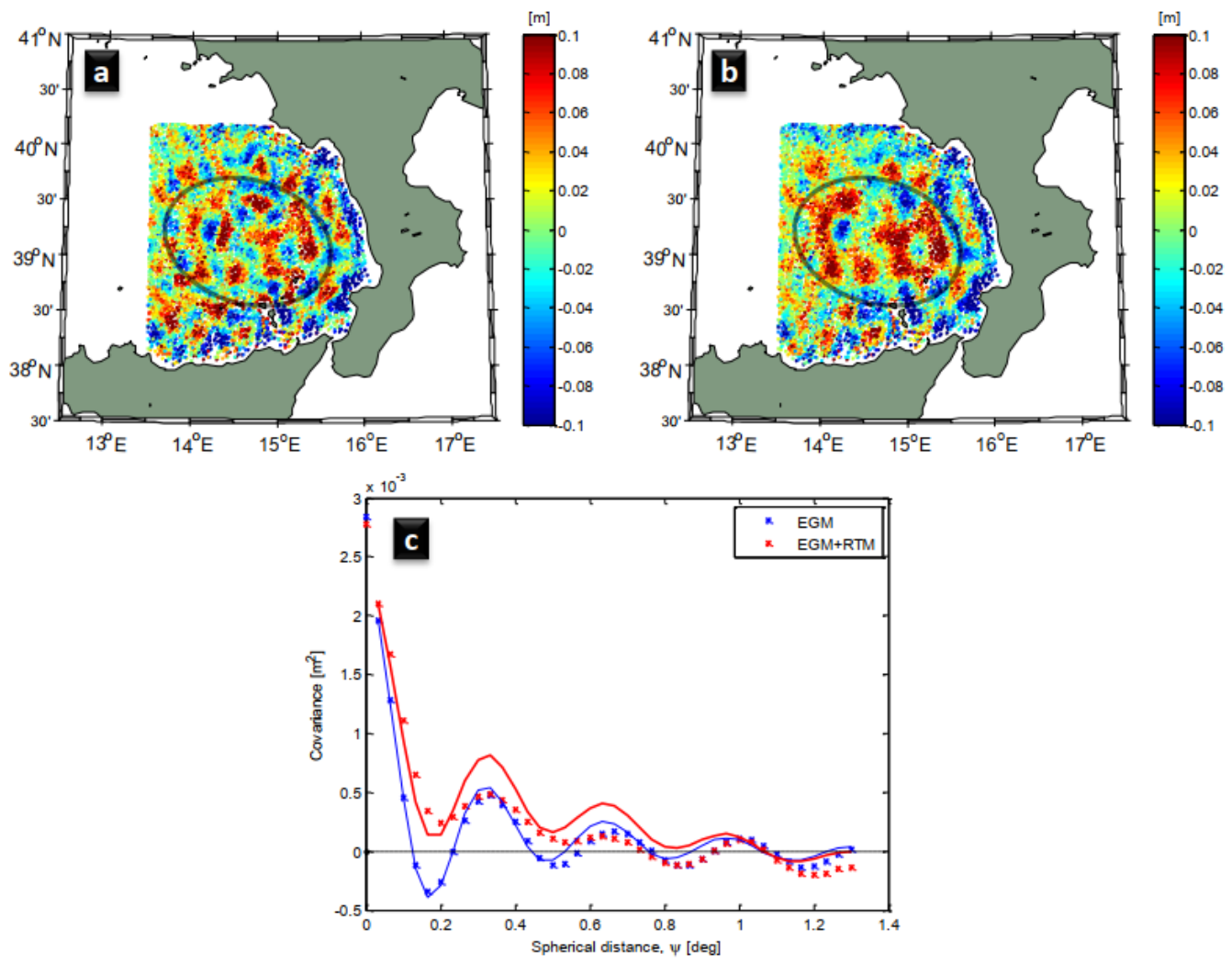

Fig. 2. Residual height anomaly from RADS dataset after cross-over adjustment (a) for only removing the EGM2008 (d/o 1080 ) (b) for removing the EGM2008 (d/o 1080) and also RTM effects (c) empirical covariance (* symbols) and Tscherning\&Rapp covariance model fitting (curved lines). The blue curves refers to (a) while the red curves refers to (b). The area bounded by ellipse has deep and flat bathymetry.

height anomalies after cross-over adjustment are shown in Fig. 1 along with the empirical covariance estimates. The residual signal remaining after removing the EGM2008 (d/o 2190) is so small with a standard deviation (std.) of $0.038 \mathrm{~m}$. When removing the full resolution EGM2008 model, the signal-to-noise ratio (SNR) in the residual field is so small and it will be hard to fit a proper covariance model as shown in Fig. $1 \mathrm{~b}$.

In this study, we intentionally preserve some signal from the EGM2008 model to increase the SNR in the residual height anomalies. Hence, we reduce the maximum spherical harmonic degree of the EGM2008 model to 1080. The shortest half-wavelength of the reference EGM2008 (d/o 1080) is around $20 \mathrm{~km}$ (10 arc-minute resolution). The wavelength is still smaller than the extent of the region $(\sim 200 \mathrm{~km})$.

The RADS residual height anomalies after removing EGM2008 (d/o 1080) and MDT with and without RTM effects are shown in Fig.2. The RTM effects are supposed to reduce the residual signal, but the residual signal is partly "enhanced" by subtracting the RTM contributions. Outside the ellipse in Fig.2b, the residual height anomalies are indeed reduced by removing RTM effects. Inside the ellipse, the signal is stronger and longer wavelength features can be observed. The bathymetry is mostly deep ( $3500 \mathrm{~m}$ ) and flat in the area bounded by the ellipse. The additional signal also distorts the empirical covariance estimates. In Fig.2c, the correlation length of height anomalies with $N^{R T M}$ removed (red curve) is apparently longer than that without removing $N^{R T M}$ (blue curve).

The long wavelength features introduced by removing $N^{R T M}$ make it hard to fit the Tscherning\&Rapp covariance model as well. Hence, we proceed without removing (or restoring) the RTM contributions in this study.

The height anomalies after the cross-over adjustment for RADS, LARS and GPOD data are shown in Fig.3. We can observe that the LARS and GPOD data are closer to the coastal lines than the RADS data and have slightly more observations. The statistics of the height anomalies are shown in Table 1. 
Table 1. Statistic of residual height anomalies after cross-over adjustment. Unit: $\mathrm{m}$

\begin{tabular}{llllll}
\hline Database & \# obs. & mean & std. & min & $\max$ \\
\hline RADS & 9471 & 0.003 & 0.059 & -0.460 & 0.265 \\
LARS & 10304 & 0.003 & 0.061 & -0.282 & 0.343 \\
GPOD & 9896 & 0.003 & 0.059 & -0.289 & 0.304 \\
\hline
\end{tabular}

Table 2. Statistic of the difference between predicted gravity anomalies from 3 different datasets, shipborne gravimetry $\Delta \mathrm{gShip}$ and EGM2008, in total 2264 samples. Based on the distance away from the nearest coastal line $(15 \mathrm{~km}), 347$ samples are located in the "Coastal area". The other 1917 points are used as "Open sea" samples. Unit: mGal

\begin{tabular}{|c|c|c|c|c|c|}
\hline & & mean & std. & $\max$ & $\min$ \\
\hline \multirow{7}{*}{ All samples } & $\Delta \mathrm{g}^{R A D S}$ Vs. $\Delta \mathrm{g}^{E G M}$ & 0.21 & 3.50 & -15.6 & 14.5 \\
\hline & $\Delta \mathrm{g}^{L A R S}$ Vs. $\Delta \mathrm{g}^{E G M}$ & 0.41 & 3.36 & -16.8 & 20.1 \\
\hline & $\Delta \mathrm{g}^{G P O D}$ Vs. $\Delta \mathrm{g}^{E G M}$ & 0.26 & 3.48 & -20.8 & 14.9 \\
\hline & $\Delta \mathrm{g}^{\text {Ship }}$ Vs. $\Delta \mathrm{g}^{E G M}$ & 0.50 & 5.13 & -18.5 & 78.9 \\
\hline & $\Delta \mathrm{g}^{R A D S}$ Vs. $\Delta \mathrm{g}^{S h i p}$ & -0.38 & 5.05 & -79.7 & 24.8 \\
\hline & $\Delta \mathrm{g}^{L A R S}$ Vs. $\Delta \mathrm{g}^{S h i p}$ & -0.18 & 4.86 & -78.7 & 18.7 \\
\hline & $\Delta \mathrm{g}^{G P O D}$ Vs. $\Delta \mathrm{g}^{\text {Ship }}$ & -0.33 & 5.03 & -79.6 & 19.5 \\
\hline \multirow{7}{*}{ Coastal area $(<15 \mathrm{~km})$} & $\Delta \mathrm{g}^{R A D S}$ Vs. $\Delta \mathrm{g}^{E G M}$ & 0.74 & 5.69 & -14.7 & 14.5 \\
\hline & $\Delta \mathrm{g}^{L A R S}$ Vs. $\Delta \mathrm{g}^{E G M}$ & 1.02 & 5.47 & -16.8 & 20.1 \\
\hline & $\Delta \mathrm{g}^{G P O D}$ Vs. $\Delta \mathrm{g}^{E G M}$ & 0.47 & 5.81 & -20.8 & 14.9 \\
\hline & $\Delta \mathrm{g}^{\text {Ship }}$ Vs. $\Delta \mathrm{g}^{E G M}$ & -0.85 & 6.63 & -18.5 & 33.5 \\
\hline & $\Delta \mathrm{g}^{R A D S}$ Vs. $\Delta \mathrm{g}^{S h i p}$ & 1.45 & 6.54 & -20.1 & 24.8 \\
\hline & $\Delta \mathrm{g}^{L A R S}$ Vs. $\Delta \mathrm{g}^{S h i p}$ & 1.73 & 5.91 & -21.9 & 18.7 \\
\hline & $\Delta \mathrm{g}^{G P O D}$ Vs. $\Delta \mathrm{g}^{\text {Ship }}$ & 1.18 & 6.61 & -21.3 & 19.5 \\
\hline \multirow{7}{*}{ Open sea (>15 km) } & $\Delta \mathrm{g}^{R A D S}$ Vs. $\Delta \mathrm{g}^{E G M}$ & 0.11 & 2.93 & -15.6 & 10.4 \\
\hline & $\Delta \mathrm{g}^{L A R S}$ Vs. $\Delta \mathrm{g}^{E G M}$ & 0.30 & 2.81 & -11.6 & 10.2 \\
\hline & $\Delta \mathrm{g}^{G P O D}$ Vs. $\Delta \mathrm{g}^{E G M}$ & 0.22 & 2.86 & -11.6 & 11.2 \\
\hline & $\Delta \mathrm{g}^{\text {Ship }}$ Vs. $\Delta \mathrm{g}^{\mathrm{EGM}}$ & 0.74 & 4.77 & -18.2 & 78.9 \\
\hline & $\Delta \mathrm{g}^{R A D S}$ Vs. $\Delta \mathrm{g}^{S h i p}$ & -0.72 & 4.66 & -79.7 & 15.3 \\
\hline & $\Delta \mathrm{g}^{L A R S}$ Vs. $\Delta \mathrm{g}^{\text {Ship }}$ & -0.53 & 4.56 & -78.7 & 18.1 \\
\hline & $\Delta \mathrm{g}^{G P O D}$ Vs. $\Delta \mathrm{g}^{\text {Ship }}$ & -0.61 & 4.64 & -79.6 & 18.1 \\
\hline
\end{tabular}

\subsection{Empirical covariance and covariance modelling}

The empirical covariances are modelled with EMPCOV module from GRAVSOFT package. For the covariance modelling, the variance term estimated by EMPCOV is excluded, due to the fact that it contains both the signal and noise, and sometimes the signal is insignificant (or very low signal-to-noise ratio). The covariance model fit to the empirical covariances are shown in Fig.4. In general, the Tscherning\&Rapp covariance model fits well with the discrete empirical covariances at the short wave- lengths. We can also observe the correlation length of altimetry data, which is around $0.1^{\circ}$ spherical distance (approx. $10 \mathrm{~km}$ resolution).

\subsection{Gravity anomalies from LSC and Validation}

The GEOCOL19 program with parallel processing option (Kaas et al., 2013) is used to derive the marine gravity anomalies along the shipborne gravity measurements from Morelli cruises(Allan and Morelli, 1971) and Bureau Gravimétrique International (BGI) database. The shipborne measurements are post-processed and downsampled to a 7.5" grid cells for the purpose of Mediterranean gravimetric geoid modelling (see GEOMED2 project for details (Barzaghi et al., 2018). To save the computation time, we further downsampled by a factor of four and get 2264 samples in the study area. The data will be used for the validations later.

The output from LSC is the residual gravity anomalies. The error estimates of the predictions have a median value of 2.38, 2.35 and $2.28 \mathrm{mGal}$ for RADS, LARS and GPOD data, respectively. The prediction error near the coastal lines tends to be higher due to the sparse altimetry ob- 

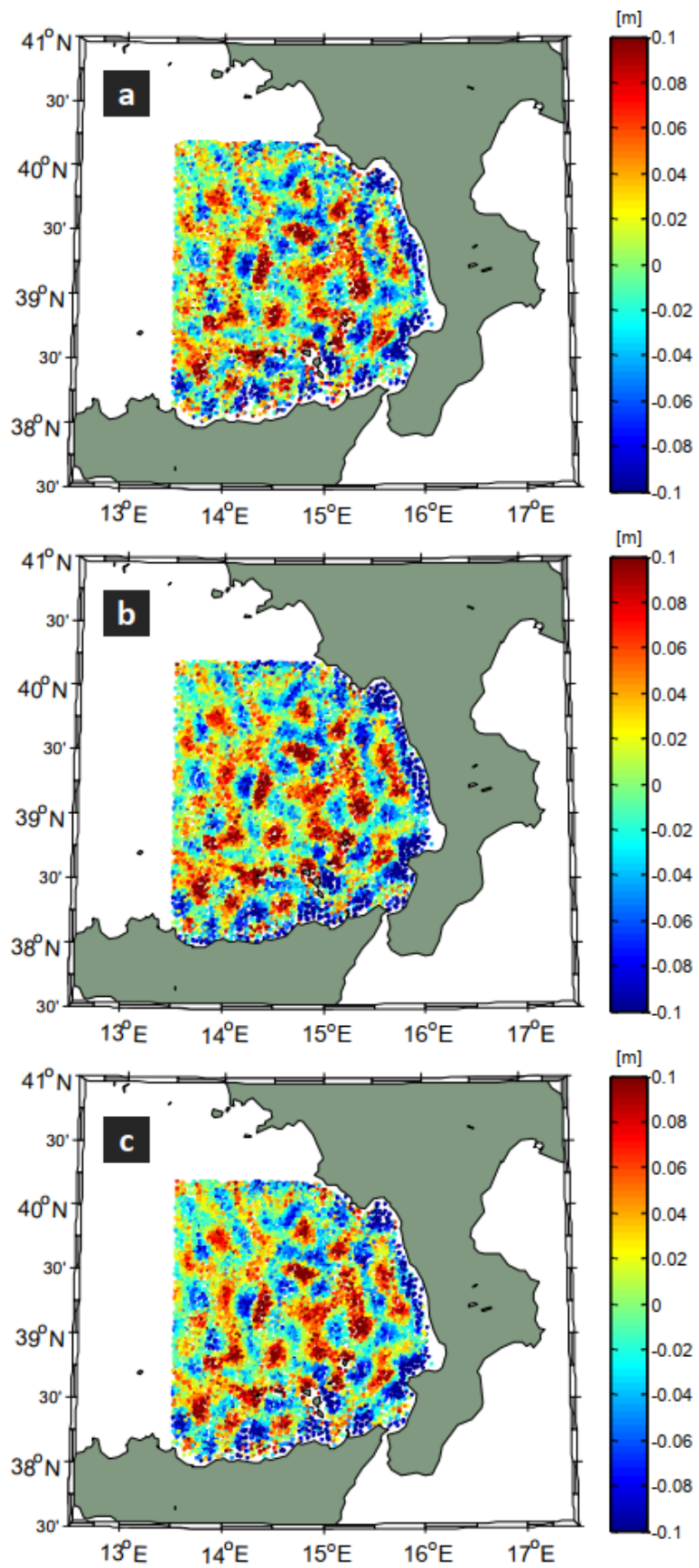

Fig. 3. Residual height anomaly after cross-over adjustment (a) RADS (b) LARS (c) GPOD. Only EGM2008 (d/o 1080) is removed.

servations. On almost all prediction points, the prediction error is smaller than $4 \mathrm{mGal}$ for LARS and GPOD data, which is significantly better than Sandwell gravity field V23.1 (Sandwell et al., 2014a) errors in the same coastal region.

We restore the full gravity signal by adding the EGM2008 gravity anomalies (d/o 1080) to the residual gravity anomalies predicted from LSC. Then, a direct com-
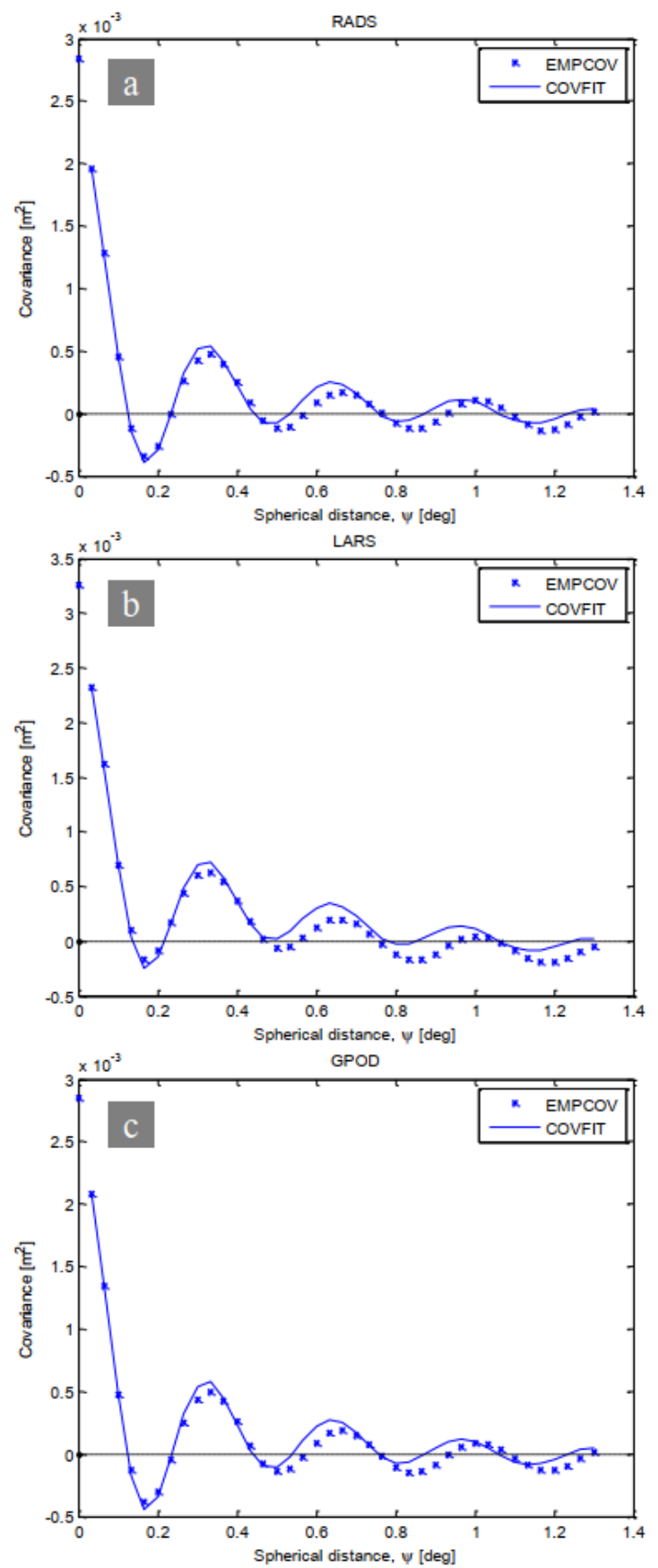

Fig. 4. Empirical covariances ( ${ }^{*}$ symbols) and covariance model fits (blue continuous curves) for residual height anomalies shown in Fig.3 (a) RADS (b) LARS (c) GPOD.

parison with shipborne measurements can be conducted. The statistics comparing predicted gravity, EGM2008 and shipborne measurements are shown in Table 2. Note that the EGM2008 and ship gravity are not error-free. The standard deviations of the differences reflects the relative precision of the predicted gravity anomalies. The altimetric gravity anomalies agree with ship measurements with 


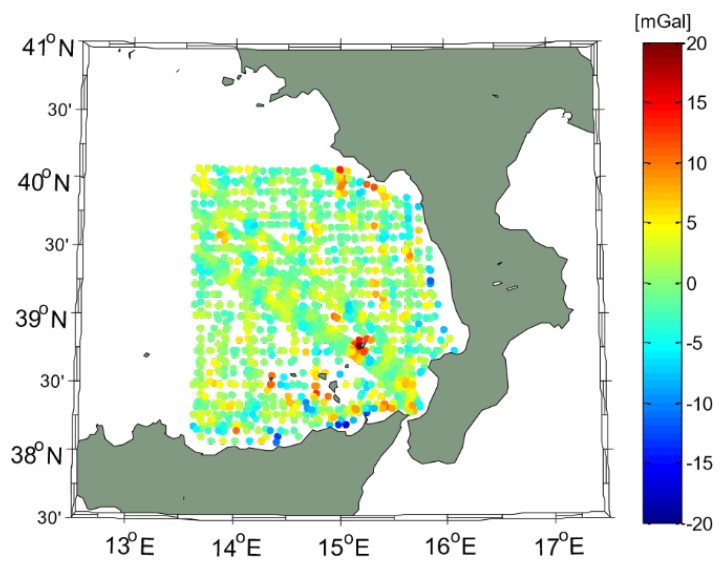

Fig. 5. Difference of LARS altimetric gravity anomalies and EGM2008 over the shipborne survey locations. In total, 2264 samples.
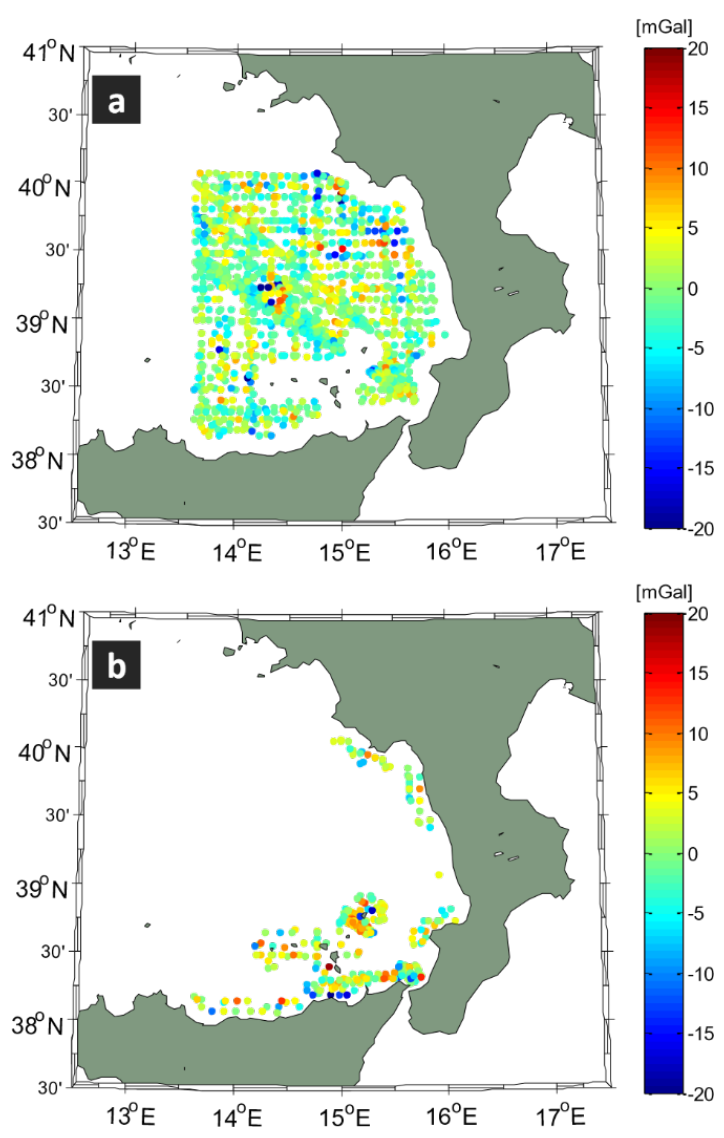

Fig. 6. Difference of (LARS) altimetric gravity anomalies and shipborne gravity (a) over the open ocean (std. $=4.56 \mathrm{mGal}$ ), (b) in the coastal area (std. $=5.91 \mathrm{mGal}$ ). Most of the "coastal area" samples are located around the Aeolian islands and north of Sicily island.

a std. of 5.05, 4.86 and $5.03 \mathrm{mGal}$, respectively. The difference of ship measurements and EGM2008 has a std. of $5.13 \mathrm{mGal}$. By using altimetry for marine gravity modelling, we get minor improvement. The relative precision of altimetric gravity anomalies compared to EGM2008 is $3.50,3.36$ and $3.48 \mathrm{mGal}$, respectively. In both crosscomparisons, the gravity anomalies predicted from LARS altimetry database have the best relative precision.

The residuals of predicted gravity anomalies (from LARS data) and EGM2008 are shown in Fig.5. The shipborne gravity samples are divided into "Coastal area" and "Open sea" based on the distance to the closest shorelines. We have 347 samples that are located within $15 \mathrm{~km}$ distance from land or islands. The rest are "Open sea" samples. The difference between gravity anomalies predicted from recent altimetry data (LARS) and shipborne gravity surveys are shown in Fig.6. We compare the predicted gravity field and EGM2008 against shipborne gravity. As shown in Table 2, in coastal areas, the std. is reduced from 6.63 $\mathrm{mGal}$ to $5.91 \mathrm{mGal}$, which is $11 \%$ improvement. In the open oceans, the improvement is smaller (only 4\%).

We assume the error sources are independent between EGM2008, shipborne gravity and predicted gravity anomalies. Thus, we can estimate the precision of the individual dataset through error propagation. This may not be a fair assumption as the gravity data or old altimetric gravity anomalies are integrated to the development of EGM2008. Take the gravity anomalies estimated from recent altimetry data (LARS) as an example. The standard deviation of the predicted gravity anomalies is $\sigma^{L A R S}=2.07$ $\mathrm{mGal}$. The error in the EGM2008 and ship measurements are $\sigma^{E G M}=2.64 \mathrm{mGal}$ and $\sigma^{\text {Ship }}=4.39 \mathrm{mGal}$, respectively. The estimates suggest that the shipborne measurements are not optimal for assessing the accuracy of the predicted gravity anomalies. Nevertheless, in this region, $2.07 \mathrm{mGal}$ of error in the altimetric gravity anomalies is quite encouraging.

\section{Summary}

Altimetry data from CryoSat-2, SARAL/Altika and Jason-1 geodetic missions are valuable for improving marine gravity not only over the open oceans, but also near the coast. In this study, we showed the potential of recent satellite altimetry in modelling the coastal marine gravity. In the test area north of Sicily island in the Mediterranean Sea, the RTM signal reduction is effective near the coastal relief but not in the deep bathymetric part in the center of study area. The deep water areas likely have sediments that buried the subseafloor structures associated with gravity. Hence, we proceeded without considering RTM contributions in this study.

Gravity field predicted from altimetry data with the most coastal coverage and retracked with the narrow 
primary peak retracker gives the best precision of 2.07 mGal. Gravity prediction error from LSC is less than 4 $\mathrm{mGal}$ near the coast. The standard deviation is $4.86 \mathrm{mGal}$ when predicted gravity anomalies are compared to shipborne gravity used for GEOMED2 project. This is slightly better than a std. of $5.13 \mathrm{mGal}$ between shipborne gravity and EGM2008. Residual gravity field with respect to EGM2008 is an enhancement to EGM2008. In particular, we got $11 \%$ improvement in the coastal area. DTU marine gravity models with improvements in the coastal zones will be incorporated to the next generation of EGM, e.g., EGM2020, in the future.

Acknowledgements: The authors would like to thank two anonymous reviewers for their constructive comments and discussions. We acknowledge the processed altimetry data from RADS, LARS database and ESA GPOD service. The ICGEM service provided geoid and gravity anomalies up to desired d/o from EGM2008. We thank GEOMED2 project for providing the shipborne gravity measurements for validations.

\section{References}

Allan, T., and C. Morelli, A geophysical study of the Mediterranean sea. NATO subcommittee on oceanographic research, Tech. rep., Technical reports, 1971.

Andersen, O. B., and P. Knudsen, The role of satellite altimetry in gravity field modelling in coastal areas, Physics and Chemistry of the Earth, Part A: Solid Earth and Geodesy, 25(1), 17-24, 2000.

Barzaghi, R., et al., Geomed2: High-resolution geoid of the Mediterranean, Springer, 2018.

Basic, T., and R. Rapp, Oceanwide prediction of gravity anomalies and sea surface heights using geos-3, Seasat, and Geosat Altimeter data and etopo5u bathymetric data, Tech. rep., Department of Geodetic Science and Surveying, The Ohio State University, Report No 416, 1992.

Bouffard, J., S. Vignudelli, P. Cipollini, and Y. Menard, Exploiting the potential of an improved multimission altimetric data set over the coastal ocean, Geophysical Research Letters, 35(10), 10.1029/2008GL033488, 2008.

Brown, G., The average impulse responce of a rough surface and its applications, IEEE Journal of oceanic engineering, 2(1), 67-74, 1977.

Døssing, A., T. M. Hansen, A. V. Olesen, J. Hopper, and T. Funck, Gravity inversion predicts the nature of the Amundsen basin and its continental borderlands near Greenland, Earth and Planetary Science Letters, 408, 132-145, 2014.

Duquenne, H., M. Everaerts, and P. Lambot, Merging a gravimetric model of the geoid with GPS/levelling data: an example in Belgium, in Gravity, Geoid and Space Missions, pp. 131-136, Springer, 2005.
Engen, Ø., L. N. Frazer, P. Wessel, and J. I. Faleide, Prediction of sediment thickness in the Norwegian-Greenland sea from gravity inversion, Journal of Geophysical Research: Solid Earth, 111(B11), 2006.

Forsberg, R., A study of terrain reductions, density anomalies and geophysical inversion methods in gravity field modelling,

Tech. rep., Ohio State Univ Columbus Dept Of Geodetic Science and Surveying, Report No 355, 1984.

Forsberg, R., and M. Sideris, Geoid computations by the multiband spherical FFT approach, Manuscripta geodaetica, 18, 82-82, 1993.

Forsberg, R., and C. C. Tscherning, The use of height data in gravity field approximation by collocation, Journal of Geophysical Research: Solid Earth, 86(B9), 7843-7854, 1981.

Forsberg, R., C. Tscherning, and P. Knudsen, An overview manual for the GRAVSOFT, Copenhagen, Denmark, 2008.

Garcia, E. S., D. T. Sandwell, and W. H. Smith, Retracking Ccryosat2, Envisat and Jason-1 radar altimetry waveforms for improved gravity field recovery, Geophysical Journal International, 196(3), 1402-1422, 10.1093/gji/ggt469, 2014.

Gommenginger, C., P. Thibaut, L. Fenoglio-Marc, G. Quartly, X. Deng, J. Gómez-Enri, P. Challenor, and Y. Gao, Retracking altimeter waveforms near the coasts, in Coastal altimetry, pp. 61-101, Springer, 2011.

Hirt, C., Prediction of vertical deflections from high-degree spherical harmonic synthesis and residual terrain model data, Journal of Geodesy, 84(3), 179-190, 2010.

Hirt, C., RTM gravity forward-modeling using topography/bathymetry data to improve high-degree global geopotential models in the coastal zone, Marine Geodesy, 36(2), 183-202, 2013.

Hwang, C., J. Guo, X. Deng, H.-Y. Hsu, and Y. Liu, Coastal gravity anomalies from retracked Geosat/GM Altimetry: improvement, limitation and the role of airborne gravity data, Journal of Geodesy, 80(4), 204-216, 2006.

Idžanović, M., V. Ophaug, and O. B. Andersen, The coastal mean dynamic topography in Norway observed by Cryosat- 2 and GOCE, Geophysical Research Letters, 44(11), 5609-5617, 2017.

Jain, M., O. B. Andersen, J. Dall, and L. Stenseng, Sea surface height determination in the arctic using Cryosat-2 SAR data from primary peak empirical retrackers, Advances in Space Research, 55(1), 40-50, 2015.

Jordan, S. K., Self-consistent statistical models for the gravity anomaly, vertical deflections, and undulation of the geoid, Journal of Geophysical Research, 77(20), 3660-3670, 1972.

Kaas, E., B. Sørensen, C. C. Tscherning, and M. Veicherts, Multiprocessing least squares collocation: Applications to gravity field analysis, Journal of Geodetic Science, 3(3), 219-223, 2013.

Kearsley, W., Non-stationary estimation in gravity prediction problems., Tech. rep., Department of Geodetic Science and Surveying, The Ohio State University, Report No 256, 1977.

Knudsen, P., Estimation and modelling of the local empirical covariance function using gravity and satellite altimeter data, Bulletin Geodesique, 61(2), 145-160, 1987.

Knudsen, P., and M. Brovelli, Collinear and cross-over adjustment of Geosat erm and Seasat altimeter data in the Mediterranean sea, Surveys in geophysics, 14(4-5), 449-459, 1993.

Moritz, H., Least-squares collocation, Reviews of Geophysics, 16(3), 421-430, 10.1029/RG016i003p00421, 1978. 
Omang, O., and R. Forsberg, How to handle topography in practical geoid determination: three examples, Journal of Geodesy, 74(6), 458-466, 2000.

Parker, R., The rapid calculation of potential anomalies, Geophysical Journal of the Royal Astronomical Society, 31(4), 447-455, 1973.

Passaro, M., P. Cipollini, S. Vignudelli, G. D. Quartly, and H. M. Snaith, Ales: A multi-mission adaptive subwaveform retracker for coastal and open ocean altimetry, Remote Sensing of Environment, 145, 173-189, 2014.

Passaro, M., S. K. Rose, O. B. Andersen, E. Boergens, F. M. Calafat, D. Dettmering, and J. Benveniste, Ales+: Adapting a homogenous ocean retracker for satellite altimetry to sea ice leads, coastal and inland waters, Remote Sensing of Environment, 211, 456-471, 2018.

Pavlis, N. K., S. A. Holmes, S. C. Kenyon, and J. K. Factor, The development and evaluation of the earth gravitational model 2008 (egm2008), Journal of Geophysical Research: Solid Earth, 117(B4), 1-38, 10.1029/2011JB008916, 2012.

Ray, C., C. Martin-Puig, M. P. Clarizia, G. Ruffini, S. Dinardo, C. Gommenginger, and J. Benveniste, SAR altimeter backscattered waveform model, IEEE Transactions on Geoscience and Remote Sensing, 53(2), 911-919, 2015.

Sandwell, D. T., R. D. Müller, W. H. Smith, E. Garcia, andR. Francis, New global marine gravity model from Cryosat-2 and Jason- 1 reveals buried tectonic structure, Science, 346(6205), 65-67, 2014a.

Sandwell, D. T., R. D. Müller, W. H. F. Smith, E. Garcia, and R. Francis, New global marine gravity model from Cryosat-2 and Jason1 reveals buried tectonic structure, Science, 346(6205), 65-67, $10.1126 /$ science.1258213, 2014b.

Scharroo, R., Rads rdsar algorithm theoretical basis document, version0. 3, cp40 project report, 2014-updated may 2016, http://www. satoc. eu/projects/CP4O/docs/tud_rdsar_atbd. pdf, 2016.

Scharroo, R., E. Leuliette, J. Lillibridge, D. Byrne, M. Naeije, and G. Mitchum, Rads: Consistent multi-mission products, in Proc. of the Symposium on, vol. 20, p. 4, 2013.

Schwarz, K., M. Sideris, and R. Forsberg, The use of FFT techniques in physical geodesy, Geophysical Journal International, 100(3), 485-514, 1990.

Sjöberg, L., A discussion on the approximations made in the practical implementation of the remove-compute-restore technique in regional geoid modelling, Journal of Geodesy, 78(11-12), 645-653, 2005.

Smith, W. H. F., and D. T. Sandwell, Bathymetric prediction from dense satellite altimetry and sparse shipboard bathymetry, Journal of Geophysical Research: Solid Earth, 99(B11), 21,80321,824, 10.1029/94JB00988, 1994.

Tscherning, C. C., and R. H. Rapp, Closed covariance expressions for gravity anomalies, geoid undulations, and deflections of the vertical implied by anomaly degree variance models., Tech. rep., Department of Geodetic Science and Surveying, The Ohio State University, Report No 208, 1974.

Verron, J., et al., The SARAL/AltiKa altimetry satellite mission, $M a$ rine Geodesy, 38(sup1), 2-21, 2015.

Vignudelli, S., P. Cipollini, L. Roblou, F. Lyard, G. P. Gasparini, G. Manzella, and M. Astraldi, Improved satellite altimetry in coastal systems: Case study of the Corsica channel (Mediterranean sea), Geophysical Research Letters, 32(7),
10.1029/2005GL022602, 2005.

Wingham, D., et al., Cryosat: A mission to determine the fluctuations in earth's land and marine ice fields, Advances in Space Research, 37(4), 841-871, 2006.

Zhang, S., and D. T. Sandwell, Retracking of SARAL/AltiKa radar altimetry waveforms for optimal gravity field recovery, Marine Geodesy, 40(1), 40-56, 2017. 